\title{
El cuento de la criada: psicoanálisis, feminismos y religión
}

\author{
The handmaid's tale | Bruce Miller | 2017
}

\section{Matías Meichtri Quintans*}

Escuela de Orientación Lacaniana (EOL) Sección Córdoba, Argentina

Recibido: 20 de julio 2019; aceptado: 8 de octubre 2019

\begin{abstract}
Resumen
El presente artículo, a partir de la serie El cuento de la criada (Atwood y Moss, 2017), aborda la historia de las mujeres y el universo de lo femenino en articulación con el psicoanálisis, intentando responder el lugar que ellas ocupan para el mismo. Así, parte desde los inicios del psicoanálisis con Freud y su apuesta a escuchar el malestar de las pibas de aquella época. El recorrido lleva a esbozar una respuesta acerca de qué es lo femenino para el psicoanálisis y que implicaría hablar de un psicoanálisis feminista. Asimismo, hace hincapié en dos significantes que toman un protagonismo inédito en el estado actual y que la serie, en tanto fenómeno que da cuenta de la actualidad, permite abordar: los feminismos y las religiones.
\end{abstract}

Palabras clave: Neopaternalismo | no relación sexual | sexuación | posición femenina | pibas | Freud

The handmaid's tale: psychoanalysis, feminisms and religion

\begin{abstract}
The present article, from the TV series The handmaid's tale (Atwood and Moss, 2017), addresses the history of women and the universe of the feminine in articulation with psychoanalysis, trying to answer the place they occupy to it. Thus, it starts from the beginning of psychoanalysis with Freud and his commitment to listen to the discomfort of the pibas of that time. The tour leads to outline an answer about what is feminine for psychoanalysis and what it would mean to speak of a feminist psychoanalysis. Likewise, it emphasizes two signifiers that take an unprecedented prominence in the current state and that the series, as a phenomenon that accounts for the present, allows addressing: feminisms and religions.
\end{abstract}

Keywords: Neopaternalism | no sexual intercourse | sexuation | female position | pibas | Freud

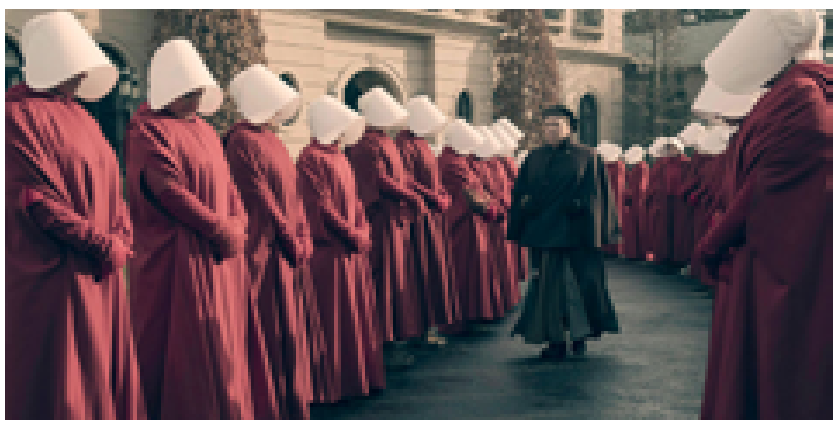

Uno de esos elementos fácilmente reconocibles, es el modo en el que la civilización muestra los cambios promovidos por el movimiento de mujeres junto a la emergencia del machismo más radical.

Cuando la psicoanalista Marie-Hélène Brousse tomó a esta serie para referirse a la acentuación de esos rasgos 
patriarcales, llamó neopaternalismo al dogma que subyace a lo largo de la trama narrativa. Esta acentuación, pareciera un retroceso en el tiempo sin embargo la novela lo ficciona en un futuro. Brousse lo ejemplifica así:

el problema [en la obra] es que todos son más o menos infértiles, y especialmente los hombres, pero hay una negación total de eso y se tiene la idea muy banal, propia de las sociedades patriarcales, de que cuando no hay un hijo en una pareja es porque la mujer es la estéril. (Brousse, 2019, p. 28)

Esta idea, aparentemente conservadora y típica de un pasado machista, forma parte de la urdimbre alrededor de la cual se trama toda la novela. Ese neopaternalismo ubica entonces un retorno de formas conocidas aunque radicalizadas, lo que da la idea de que se trata de algo nuevo, precisamente, por que las funciones que se hacían derivar de la figura del padre ya no son tales.

El psicoanálisis desde hace bastante tiempo sostiene que esa función tributaria de un orden simbólico, cayó. Lo que emerge es la vertiente más bien imaginaria, presente en la aparición más cruel de un amo feroz.

2

La proyección del episodio piloto en el décimo quinto Ciclo de Cine y Psicoanálisis de la Universidad Nacional de Córdoba, es una buena ocasión para situar una breve reflexión a propósito del nombre que este año la comisión organizadora eligió para interpretar la época: Pibas.

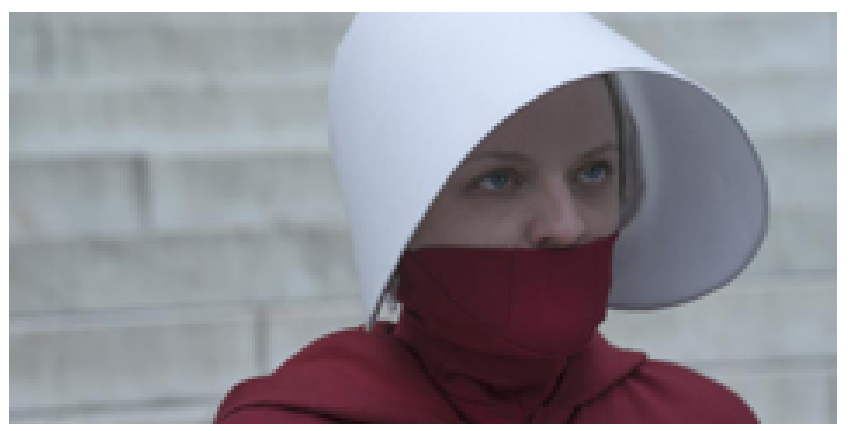

Sigmund Freud tenía una frase respecto del nacimiento del psicoanálisis, decía: "no brotó de una roca ni cayó del cielo" (Freud, 1979, p. 203), diciendo también que no hay que olvidar ni las épocas ni los estados que lo precedieron. Se puede extraer una buena indicación a la hora de pensar los síntomas sociales, es decir, pensar su existencia en función de la época.

Entonces: si uno reflexiona, como con un síntoma, sobre el contexto en el que surge el psicoanálisis, encon- tramos una sociedad represiva dotada de una doble moral que Freud vino a cuestionar.

Cuestiona el Discurso del Amo, es decir que cuestiona el sentido instituido de esa época y lo hace a partir de detenerse a escuchar el malestar de jovencitas, de $p i-$ bas como Anna O. que tenía 21 años o Dora que visita a Freud por primera vez a los 18 años, Elizabeth von $\mathrm{R}$ tenía 24 , Mathilde $19 . .$.

Estas pibas le muestran a Freud toda una fenomenología sintomática que rompe con el saber instituido, el saber científico de la neurología y de la psiquiatría de la época. Encontramos que en lugar de acusarlas de histrionismo, locura, exageración; en lugar de minimizar su queja o de recurrir a los padres de las pacientes para acallarlas, manicomializarlas o encerrarlas, Freud hace una apuesta. Se pregunta si no son las disciplinas mismas las que no están a la altura de la época, de los síntomas que la época genera.

Esta apuesta le permite descubrir el inconsciente y entrar en un universo nuevo, el de la realidad psíquica que, a medida que lo descubre, lo revela y lo teoriza. Y lo hace dándole lugar al relato de mujeres jóvenes, de pibas, que como ocurre hoy en numerosos lugares, empujan con su voz los límites de lo instituido.

Esto nos lleva nuevamente a El cuento de la criada (Atwood, 1985), que refleja un rasgo propio de la historia de las mujeres y, podríamos decir, del universo de femenino:

la historia de las mujeres es, en cierto modo, la de su acceso a la palabra. (...) Pero la audición directa de su voz depende del acceso de las mujeres a los medios de expresión: el gesto, la palabra, la escritura (...) cuestión de penetración en un dominio sagrado y siempre marcado por las fronteras fluctuantes de lo permitido y lo prohibido. (Perrot y Duby, 2000, p. 25)

Lo que nos muestra la serie es ese estado de prohibición sobre las mujeres, a quienes no le está permitido leer ni escribir. Reducida a sus óvulos, la protagonista puede ver, oír y callar.

En la edición de 2018 del libro El cuento de la criada, hay una introducción que la autora escribe para relatar el proceso que implicó esa obra: sus premisas principales, las formas que fue tomando al ser adaptada para una versión fílmica, una ópera, un ballet etc., las diversas situaciones de las que se nutrió -entre las que figura "el robo de niños en Argentina por parte de los generales" (Atwood, 2018, p. 18)- y tres preguntas, que resumen lo que habi- 
tualmente los lectores le dicen: " $\dot{ }$ El cuento de la criada es una novela feminista? ¿El cuento de la criada es una novela en contra de la religión? ¿El cuento de la criada es una predicción?" (pp. 15-17).

El interés por la última pregunta no radica en que se trata de una novela futurista, más bien se trata de un fenómeno que dice de la actualidad. En este sentido, uno podría extraer dos significantes que se ponen en cuestión en las dos primeras preguntas para ubicar el estado actual de nuestra civilización donde, al menos en Latinoaméri$\mathrm{ca}$, los feminismos y las religiones toman un protagonismo inédito.

Lo hemos visto en Argentina con el debate generado alrededor del Proyecto de Ley de Interrupción Voluntaria del Embarazo, en ese escenario el movimiento de mujeres irrumpió en la escena pública con gran impacto en la agenda política. Hay que decir que este impacto es producto de una historia de resistencia y reclamos por los derechos a favor de la igualdad y también el reconocimiento de los colectivos de disidencia sexual.

Ahora bien, en paralelo tenemos el significante religión que denota no solo el auge evangélico y sus logros electorales, sino también aquellas estrategias retóricas que se oponen a la denominada ideología de género.

Para el psicoanálisis no son ajenos los significantes religión y feminismos, por el contrario, hay que decir que aunque no se diga de él que sea religioso o feminista, es verdad que bordean las mismas discusiones, sólo que el psicoanálisis no pretende un saber universal sobre el goce, como sí lo hace la religión: "dar un sentido a las cosas que antes eran las cosas naturales” (Lacan, 1974, p. 79).

Por otro lado, y no menos importante, el psicoanálisis para nada sostiene la creencia en una naturaleza recíproca entre el hombre y la mujer. Precisamente en ese punto, Lacan dijo "no hay relación sexual" (Lacan,
1972-73, p. 46) lo que debe ser traducido como no hay nada en la naturaleza que diga cómo deben relacionarse los cuerpos sexuados.

Lo que releva el psicoanálisis, es que cada quién deberá hacer un esfuerzo por situarse bajo una categoría que diga algo de su sexuación frente a los demás. Ahora bien, Lacan señala que esto no es sin conflicto, para eso recurre en 1957 al siguiente apólogo:

un tren llega a la estación. Un muchachito y una niña, hermano y hermana, en un compartimiento están sentados el uno frente a la otra del lado en que la ventanilla que da al exterior deja desarrollarse la vista de los edificios del andén a lo largo del cual se detiene el tren: “ ¡Mira, dice el hermano, estamos en Damas! - ¡Imbécil!, contesta la hermana, ¿no ves que estamos en Caballeros?” (...) Caballeros y Damas serán desde ese momento para esos dos niños dos patrias hacia las que sus almas tirarán cada una con un ala divergente, y sobre las cuales les será tanto más imposible pactar cuanto que, siendo en verdad la misma, ninguno podría ceder en cuanto a la preeminencia de la una sin atentar contra la gloria de la otra. (Lacan, 1957, p. 480)

El conflicto está dado, no sólo porque caballeros y damas son sólo significantes ligados al uso corriente del lenguaje, sino porque ninguno va a ceder en su convicción, en lo que quiere decir damas o caballeros, sin atentar contra el otro que se sitúa como diferente. Es una punta para pensar las diversas formas de violencia hacia lo que aparece como otredad.

Para el psicoanálisis, lo femenino no tiene nada que ver con el género, instala una asimetría en relación a la posición masculina. Está por fuera de la reducción fálica, por lo que su naturaleza implica un suplemento, con lo cual cabe interrogarse sobre las consecuencias de hacer existir hoy un psicoanálisis feminista cuando desde los inicios su posición ha sido la de no rechazar la "originalidad de la posición femenina” (Laurent, 1999, p. 115).

\section{Referencias}

Atwood, M. (1985). El cuento de la criada. España: Salamandra.

Brousse, M-H. (abril, 2019). ¿Qué madres hoy? Bitácora Lacaniana. Revista de Psicoanálisis de la Nueva Escuela Lacaniana. Volúmen (6).

Freud, S. (1979). Breve informe sobre el psicoanálisis. Obras Completas. Tomo XIX. Argentina: Amorrortu.

Perrot, M. y Duby, G. (2000). Historia de las Mujeres. España: Santillana.

Lacan, J. (1957). La instancia de la letra en el inconsciente o la razón desde Freud. Escritos I. México: Siglo XXI.

Lacan, J. (1972-1973). Aun. El seminario de Jacques Lacan. Libro 20. España: Paidós.

Lacan, J. (1974). El triunfo de la religión: precedido de Discurso a los católicos. Argentina: Paidós.

Laurent, E. (1999). Posiciones femeninas del ser. Argentina: Tres Haches.

Miller, B. (productor). (2017-). El Cuento de la Criada [serie de televisión]. Estados Unidos: HBO- Paramount Channel. 